\title{
THE $s$-CONVEX ORDERS AMONG REAL RANDOM VARIABLES, WITH APPLICATIONS
}

\author{
Michel Denuit, Claude Lefevre And Moshe Shaked
}

\begin{abstract}
In this paper, new classes of stochastic order relations are introduced. These can be seen as extensions of the usual convex order and are closely related to the orderings discussed in Lefèvre and Utev (1996), as well as to the stochastic dominances in economics and stop-loss orders in actuarial sciences. These classes are studied in detail, including properties, characterizations, sufficient conditions, and extrema with respect to these orderings in different sets of distribution functions. Some applications illustrate the theory.
\end{abstract}

Mathematics subject classification (1991): 60E15.

Key words and phrases: $s$-convex orders, $s$-increasing convex orders, convexity of higher order, Tchebycheff systems, queueing theory, insurance.

\section{REFERENCES}

[1] Bullen, P. S. (1971), A criterion for $n$-convexity, Pacific Journal of Mathematics 36, 81-98.

[2] Cambanis, S. AND Simons, G. (1982), Probability and expectations inequalities, Zeitschrift für Wahrscheinlichkeitstheorie und verwandte Gebiete 59, 1-25.

[3] Daley, D. J. AND RolsKi, T. (1984), Some comparability results for waiting times in single- and many-server queues, Journal of Applied Probability 21, 887-900.

[4] DenUit, M. AND LefÈVRE, Cl. (1997), Some new classes of stochastic order relations among arithmetic random variables, with applications in actuarial sciences, Insurance: Mathematics and Economics 20, $197-213$.

[5] DenUit, M., LeFÈvRE, Cl. AND UtEV, S. (1997), Discrete $s$-convex and $s$-increasing convex orderings, Institut de Statistique et de Recherche Opérationnelle, Université Libre de Bruxelles, Preprint 61, Brussels.

[6] Dharmadhikari, S. W. And Joag-Dev, K. (1988), Unimodality, Convexity, and Applications, Academic Press, New York.

[7] FISHBURN, P. C. (1976), Continua of stochastic dominance relations for bounded probability distributions, Journal of Mathematical Economics 3, 295-311.

[8] FishbuRn, P. C. (1980), Continua of stochastic dominance relations for unbounded probability distributions, Journal of Mathematical Economics 7, 271-285.

[9] Johnson, N. L., KotZ, S. And Balakrishnan, N. (1995), Continuous Univariate Distributions (Vol. II, 2nd Edition), Wiley, New York.

[10] KAAS, R. AND HESSELAGER, O. (1995), Ordering claim size distributions and mixed Poisson probabilities, Insurance: Mathematics and Economics 17, 193-201.

[11] KaAs, R., Van HeerwaArden, A. E. And Goovaerts, M. J. (1994), Ordering of Actuarial Risks, CAIRE Education Series, Volume I, CAIRE, Brussels.

[12] KarLin, S. (1968), Total Positivity, Stanford University Press, Stanford, California.

[13] Karlin, S. AND NoviKofF, A. (1963), Generalized convex inequalities, Pacific Journal of Mathematics 13, 1251-1279. 
[14] Karlin, S. And StUdDen, W. J. (1966), Tchebycheff Systems: With Applications in Analysis and Statistics, Wiley, New York.

[15] LeFÈVRe, Cl. AND Utev, S. (1996), Comparing sums of exchangeable Bernoulli random variables, Journal of Applied Probability 33, 285-310.

[16] LEVY, H. (1992), Stochastic dominance and expected utility: Survey and analysis, Management Sciences 38, 555-593.

[17] LindSAY, B. AND ROEDER, K. (1997), Moment-based oscillation properties of mixture models, Annals of Statistics 25, 378-386.

[18] MAKOWSKI, A. M. (1994), On an elementary characterization of the increasing convex ordering, with an application, Journal of Applied Probability 31, 834-840.

[19] Marshall, A. W. (1991), Multivariate stochastic orderings and generating cones of functions, in Stochastic Orders and Decision under Risk, Eds. K. Mosler and M. Scarsini, IMS Lecture Notes Monograph Series, 231-247.

[20] MÜLlER, A. (1996), Ordering of risks: A comparative study via stop-loss transforms, Insurance: Mathematics and Economics 17, 215-222.

[21] MÜLlER, A. (1997), Stochastic orderings generated by integrals: a unified study, Advances in Applied Probability 29, 414-428.

[22] OJA, H. (1981), On location, scale, skewness and kurtosis of univariate distributions, Scandinavian Journal of Statistics 8, 154-168.

[23] Pečarić, J. E., Proschan, F. and Tong, Y. L. (1992), Convex Functions, Partial Orderings, and Statistical Applications, Academic Press. New York.

[24] Popoviciu, T. (1933), Sur quelques propriétés des fonctions d'une ou de deux variables réelles, Mathematica 7, 1-85.

[25] Popoviciu, T. (1940), Introduction à la théorie des différences divisées, Bulletin Mathématique de la Société Roumaine des Sciences $\mathbf{4 2}$ 65-78.

[26] Popoviciu, T. (1942), Notes sur les fonctions convexes d'ordre supérieur (IX), Bulletin Mathématique de la Société Roumaine des Sciences 43, 85-141.

[27] RACHEV, S. T. AND RÜSCHENDORF, L. (1990), Approximation of sums by compound Poisson distributions with respect to stop-loss distances, Advances in Applied Probability 22, 350-374.

[28] Roberts, A. W. And Varberg, D. E. (1973), Convex Functions, Academic Press, New York.

[29] ROLSKI, T. (1976), Order relations in the set of probability distribution functions and their applications in queueing theory, Dissertationes Mathematicae 132, 5-47.

[30] Shaked, M. AND Shanthikumar, J. G. (1994), Stochastic Orders and Their Applications, Academic Press, San Diego.

[31] ShaKed, M. AND Wong, T. (1995), Preservation of stochastic orderings under random mapping by point processes, Probability in the Engineering and Informational Sciences 9, 563-580.

[32] Stoyan, D. (1983), Comparison Methods for Queues and Other Stochastic Models, Wiley, New York.

[33] WhiTT, W. (1986), Stochastic comparisons for non-Markov processes, Mathematics of Operations Research 11, 608-618. 